\title{
Mathematical Models of the Complete Course of HIV Infection and AIDS
}

\author{
R. PAUL DUFFIN and RICHARD H. TULLIS* \\ Aethlon Medical, Inc. 3344 Industrial Court, Suite 1W, San Diego, CA 92121, USA
}

(Received 18 March 2002; In final form 26 September 2002)

\begin{abstract}
Mathematical models of HIV infection are important to our understanding of AIDS. However, most models do not predict both the decrease in CD4 $+\mathrm{T}$ cells and the increase in viral load seen over the course of infection. By including terms for continuous loss of CD4 $+\mathrm{T}$ cells and incorporating alteration in viral clearance and viral production, two new models have been created that accurately predict the dynamics of the disease. The first model is a clearance rate reduction model and is based on a $10 \%$ per year decrease in both viral clearance and CD4 $+\mathrm{T}$ cell levels. A macrophage reservoir model incorporating the observation that macrophage viral production increases up to 1000 fold in the presence of opportunistic infections that become increasingly common as disease progresses. Both viral clearance and macrophage reservoir models predict the expected decrease in $\mathrm{T}$ cell levels and rise in viral load observed at the onset of AIDS.
\end{abstract}

Keywords: AIDS; Mathematical modeling; HIV; Macrophage reservoir; Viral clearance

\section{INTRODUCTION}

For most people, infection with HIV is the start of a progressive illness that results in death due to the increasing occurrence of opportunistic infections. The ultimate cause is the progressive degradation of the immune system by the virus resulting in AIDS. Mathematical models have been important to the study of AIDS. However, most current models do not predict the increase in viral load seen during the onset of AIDS. In the absence of a comprehensive model, applying quantitative mathematical techniques to test various explanations for AIDS to accurately predict the full course of disease has been problematic. Through the development of new models we hope to help clarify how HIV causes AIDS and perhaps aid in its solution.

HIV infection is characterized by three major phases: a peak in viral load following initial infection, a quasi steady state or latent phase where viral load rises slowly and CD4 $+\mathrm{T}$ cell counts fall for up to 10 years, and finally a dramatic rise in virus and a loss of CD4 $+\mathrm{T}$ cells associated with the development of AIDS (Pantaleo et al., 1993).

Recent models, such as those shown in Fig. 1, predict the early phases of disease but do not predict the decrease in $\mathrm{CD} 4+\mathrm{T}$ cell counts and rise in peripheral virus seen in
AIDS (Kapadvanjwala and Sofer, 1989; Perelson and Nelson, 1999; Stafford et al., 2000; Gumel et al., 2001). Viral production is based exclusively on CD4 $+\mathrm{T}$ cells, and all rates are considered to remain constant. Thus, as $\mathrm{T}$ cell counts drop in these models, so must the viral load. The paradox of a high viral load in the absence of normal $\mathrm{T}$ cell levels has yet to be solved satisfactorily.

dos Santos and Coutinho (2001) have recently reported a lymph node lattice model that predicts all three phases of the disease. In this model, CD4 $+\mathrm{T}$ cells are redistributed to the lymph nodes where the entire course of infection is hypothesized to occur. However, studies indicate that lymph nodes deteriorate over the course of infection indicating a long-term loss of lymphocytes, which is incompatible with the model (Rosenberg et al., 1994; Orenstein et al., 1997; Maas et al., 1998; Bouhdoud et al., 2000). Additionally, calculations based on several studies indicate that a large portion of the virus may be in the peripheral blood. In a typical patient, $10^{9}-10^{10}$ virus particles are produced per day in the entire body (Ho et al., 1995; Perelson et al., 1996). Assuming that the entire viral production enters the $5000 \mathrm{ml}$ of blood in an average person, the concentration of the virus would be $2 \times$ $10^{5}-2 \times 10^{6}$ copies per $\mathrm{ml}(\mathrm{cpm})$. Given a half-life of virus in blood of $6 \mathrm{~h}$ (Perelson et al., 1996), in a $24 \mathrm{~h}$ period $94.25 \%$ of the virus would have been cleared leaving

*Corresponding author. Tel./Fax: +1-858-793-8730. E-mail: rhtullis@ aethlonmedical.com 

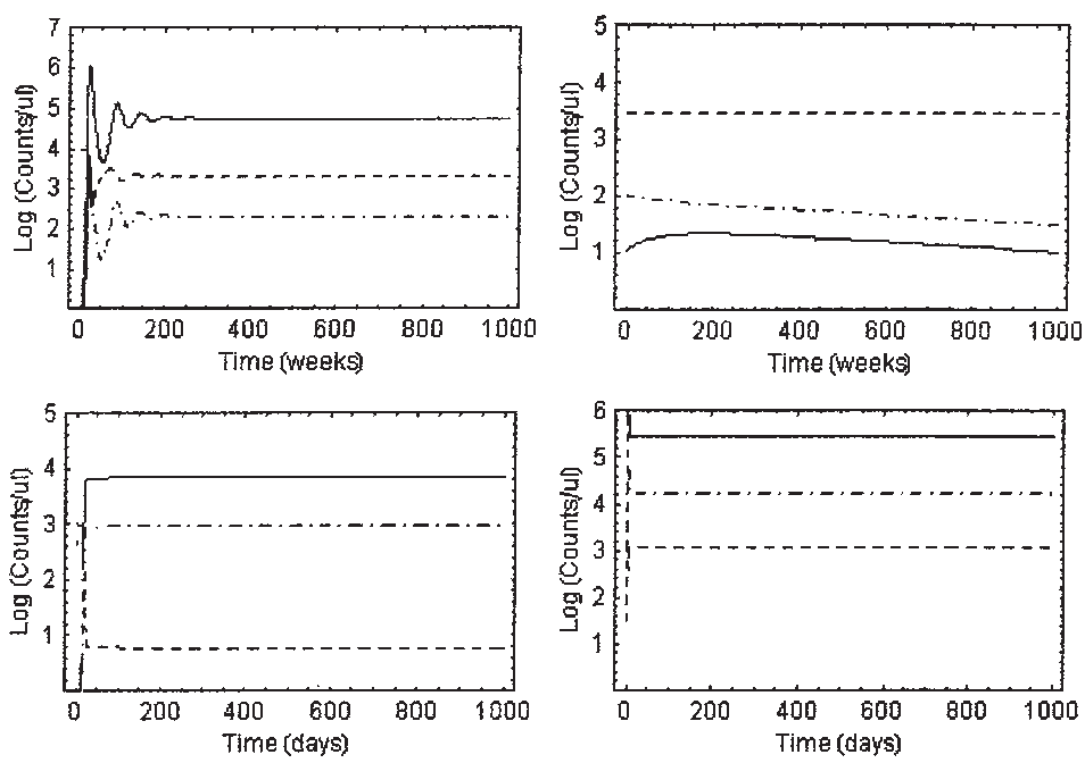

FIGURE 1 Recent mathematical models of AIDS. Clockwise from top left: Kapadvanjwala and Sofer, 1989; Perelson and Nelson, 1999; Stafford et al., 2000; Gumel et al., 2001. Virus (-), CD4 + T cells (- -) and infected CD4 + T cells (-.-) Note: early dynamics are predicted, but not the fall of $\mathrm{CD} 4+\mathrm{T}$ cells and rise in virus late in infection.

a final viral load of $13,500-135,000 \mathrm{cpm}$. Since these values are in good agreement with the typical viral loads reported for HIV patients in steady state measurements (Schacker et al., 1996; Stafford et al., 2000), it would seem that a large proportion of the virus produced each day actually enters the blood. Thus, any proposed model should account for both lymphatic and peripheral increases in viral load.

The dos Santos and Coutinho (2001) model represents just one explanation for the dynamics of an HIV infection. There are two further explanations which could account for high viral loads in the absence of normal $\mathrm{CD} 4+\mathrm{T}$ cell counts. One of the hallmarks of AIDS is the inability of the body to efficiently clear infections of all kinds (Hansen et al., 1985; Barr, 1992; Matsuo et al., 2001). Thus, it is reasonable to hypothesize that as HIV infection progresses to AIDS, the immune system loses the ability to clear virus efficiently, resulting in a longer residence time for the virus population. We term this the viral clearance reduction hypothesis.

Another reasonable explanation is that there are other viral reservoirs that become larger or more active as $T$ cells are lost and HIV infection progresses to AIDS. Although several cell types aside from CD4 $+\mathrm{T}$ cells can become productively infected, the prime candidate for such a reservoir seems to be HIV infected macrophages (Igarashi et al., 2001). Infected macrophages are typically thought to account for less than $1 \%$ of the viral load early in infection. However, in the presence of opportunistic infections and other cellular factors, the viral production in these same cells can sharply increase (Kalter et al., 1991; Orenstein et al., 1997; Moriuchi et al., 1998). Increased viral output coupled with the long life of macrophages (Perelson et al., 1996) may account for the increasing viral load seen in AIDS. We term this the macrophage reservoir model.

We address these issues using a simple target-celllimited model with terms to account for a decreasing $\mathrm{CD} 4+\mathrm{T}$ cell count, decreasing clearance rate, and release of virus from a macrophage reservoir. Although the hypotheses are formally independent, it should also be clear that a combination of the two is possible.

\section{EQUATION PARAMETERS}

\section{Patient Data}

Viral concentrations for the early phase of infection (up to day 500) were taken from 10 patients published by Stafford et al. (2000). Additional early phase data and viral concentrations from later in disease were obtained from cumulative patient data (Fauci et al., 1996). These data were then used to compare predicted and observed viral load and CD4 $+\mathrm{T}$ cell counts.

\section{The Equations}

The equations below were taken from Stafford et al. (2000) and include activated CD4 $+\mathrm{T}$ cells $(T)$, infected CD4 + $\mathrm{T}$ cells $(T i)$ in cells/ul, and virus concentration $(V)$ in cpm

$$
\begin{gathered}
\frac{\mathrm{d} T(t)}{\mathrm{d} t}=\lambda_{\mathrm{T}}-d_{\mathrm{T}} T-k_{\mathrm{T}} T V, \quad T(0)=T_{0} \\
\frac{\mathrm{d} T \mathrm{i}(t)}{\mathrm{d} t}=k_{\mathrm{T}} T V-\delta_{\mathrm{T}} T, \quad T i(0)=T i_{0} \\
\frac{\mathrm{d} V(t)}{\mathrm{d} t}=\pi_{\mathrm{T}} T i-c V, \quad V(0)=V_{0}
\end{gathered}
$$


where $\lambda=\mathrm{d} T_{0}$ is the rate of CD4 T cell production, $k_{\mathrm{T}}$ is the rate of infection of T cells, $d_{\mathrm{T}}$ is the death rate of normal $\mathrm{T}$ cells, $\delta_{\mathrm{T}}$ is the death rate of productively infected cells, $\pi_{\mathrm{T}}$ is the rate of virus production (virions/cell/day) and $\mathrm{c}$ is the clearance rate constant for the virus.

Target-cell-limited models like this have been used in other studies as well (Nowak and Bangham, 1996; Bonhoeffer et al., 1997). The Stafford model assumes that activated $\mathrm{CD} 4+\mathrm{T}$ cells are the primary targets for the virus (Schnittman et al., 1990). Activated CD4 + T cells represent approximately $1 \%$ of the total CD4 $+\mathrm{T}$ cell population (Sachsenberg et al., 1998). Since there are an average of $1000 \mathrm{~T}$ cells/ul in normal blood (Perelson and Nelson, 1999), $T_{0}=10$ cells $/$ ul. $\mathrm{Ti}_{0}=0$ since initially no $\mathrm{T}$ cells are infected, and $V_{0}=1 \times 10^{-6} \mathrm{ml}^{-1}$ representing an arbitrarily small amount of virus present immediately after infection (Stafford et al., 2000). The terms of the equations are summarized in Table I.

The Stafford model does not predict a change in $\mathrm{T}$ cell counts seen in the development of AIDS. In contrast HIV infected patients $\mathrm{T}$ cell counts drop steadily over the course of infection due to decreasing thymic function or a reduction in post-thymic CD4 $\mathrm{T}$ cell proliferation (Douek et al., 1998; Douek et al., 2001). Based on patient data from Fauci et al. (1996), the rate of loss of CD4 + T cells was estimated at $10 \%$ per year after an initial drop of $40 \%$ in the first year (Fig. 2). The calculated $10 \%$ drop in $\mathrm{CD} 4+\mathrm{T}$ cell matched the data very well. From this drop we derive the average loss of $\mathrm{T}$ cell production on any given day $(f=0.00028 \mathrm{t})$. Thus the new production rate of activated T cells becomes $\lambda_{t}=\left(\mathrm{d} T_{0}\right)(1-f)$. Substituting

TABLE I Description of variables and constants

\begin{tabular}{|c|c|c|}
\hline Terms & Description of variables and constants & Values (/ul) \\
\hline$\lambda_{\mathrm{T}}$ & Rate of production of $\mathrm{T}$ cells & $\mathrm{d} T_{0} /$ day \\
\hline$\lambda_{t}$ & $\begin{array}{l}\text { Rate of production of T } \\
\text { cells with decay term }(f)\end{array}$ & $\mathrm{d} T_{0}(1-f) /$ day \\
\hline$f$ & $\begin{array}{l}\text { Decay of } \mathrm{T} \text { cell production } \\
\text { over course of infection (10\%/year) }\end{array}$ & $(0.00028 \mathrm{t})$ \\
\hline$\lambda_{\mathrm{M}}$ & Rate of production of macrophages & $\mathrm{d} M_{0}(/$ day $)$ \\
\hline$d_{\mathrm{T}}$ & Natural death rate of healthy $\mathrm{T}$ cells & $0.01 /$ day \\
\hline$d_{\mathrm{M}}$ & $\begin{array}{l}\text { Natural death rate of healthy } \\
\text { macrophages }\end{array}$ & $0.0037 /$ day \\
\hline$k_{\mathrm{T}}$ & Viral infection rate $(\mathrm{CD} 4+\mathrm{T}$ cells $)$ & $0.00027 /$ virus-day \\
\hline$k_{\mathrm{M}}$ & Viral infection rate (macrophages) & $0.00027 /$ virus-day \\
\hline$\delta_{\mathrm{T}}$ & Death rate of infected $\mathrm{T}$ cells & $0.39 /$ day \\
\hline$\delta_{\mathrm{M}}$ & Death rate of infected macrophages & $0.024 /$ day \\
\hline$\pi_{\mathrm{T}}$ & Viral production per $\mathrm{T}$ cell & $850 /$ day \\
\hline$\pi_{\mathrm{M}}$ & Viral production per macrophage & $0.1 \times 10^{3 f} /$ day \\
\hline$c$ & Clearance rate of the virus & 3/day \\
\hline$c_{t}$ & $\begin{array}{l}\text { Reducing clearance rate of virus } \\
\text { over time }\end{array}$ & $\mathrm{c}(1-f)$ \\
\hline$T$ & Uninfected activated CD4+ T cells & $T_{0}=10$ \\
\hline $\mathrm{Ti}$ & Infected CD4 $+\mathrm{T}$ cells & $T i_{0}=10$ \\
\hline$V$ & Virus produced by $\mathrm{T}$ cells & $V_{0}=10^{-6}$ \\
\hline$M$ & Uninfected macrophages & $M_{0}=200$ \\
\hline $\mathrm{Mi}$ & Infected macrophages & $M i_{0}=0$ \\
\hline$V^{*}$ & $\begin{array}{l}\text { Total virus from } \mathrm{T} \text { cells } \\
\text { and macrophages }\end{array}$ & $V_{0}^{*}=10^{-6}$ \\
\hline
\end{tabular}

this new expression, $\lambda_{t}$, for $\lambda_{\mathrm{T}}$ now accurately reflects the gradual loss of $\mathrm{T}$ cells. As expected, this modification made to the model in terms of $\lambda_{t}$ does not appreciably affect the predictions in the first year.

\section{THEORY I. VIRUS CLEARANCE RATE REDUCTION MODEL}

\section{Modification of Clearance Rate Term}

Research indicates that early in infection, CD4 $+\mathrm{T}$ cells account for more than $90 \%$ of the productively infected cells in the body (Haase, 1999). If CD4 + T cells remain the main source of virus throughout the course of infection, then the relationship between the immune system and the virus must change. It is possible that an HIV weakened immune system may lose the ability to clear virus efficiently, as it does with many types of pathogens (Hansen et al., 1985; Barr, 1992; Matsuo et al., 2001). Though some studies suggest that clearance rates do not change throughout infection (Ho et al., 1995), there is a significant amount of variation in the measurements derived from different studies (Ho et al., 1995; Mittler et al., 1999; Ramratnam et al., 1999). Thus, it is reasonable to hypothesize changes in viral clearance rates as we have done here. For the purpose of this model, we assume that the clearance rate of the virus, $c$, decays at the same rate as the activated $\mathrm{T}$ cell concentration. Thus, $\mathrm{c}_{t}=\mathrm{c}(1-f)$. Figure 3 shows the kinetics of the entire course of infection when this term is added.

\section{Model Kinetics}

As shown in Fig. 3, the shape of the theoretical curve follows the patient data well. When viral clearance drops below some critical value, viral load actually increases even as T cells continue to decrease. At this point, any virus introduced into the system persists for a considerable period of time.

The only noticeable discrepancy is that the Fauci et al. (1996) data reach a steady state viral load approximately 10 times lower than the data presented in Stafford et al. (2000). This is likely due to increasingly sensitive viral quantification techniques, such as RT PCR, which have been improved over the past several years.

This model strongly suggests that small changes in viral clearance can account for large changes in peripheral viral load, a concept that to date has been largely ignored.

\section{THEORY II. THE MACROPHAGE RESERVOIR MODEL}

Recent data have supported the concept of infected macrophages as a second reservoir capable of sustaining high viral loads late in infection (Orenstein et al., 1997; Igarashi et al., 2001). In the presence of opportunistic 

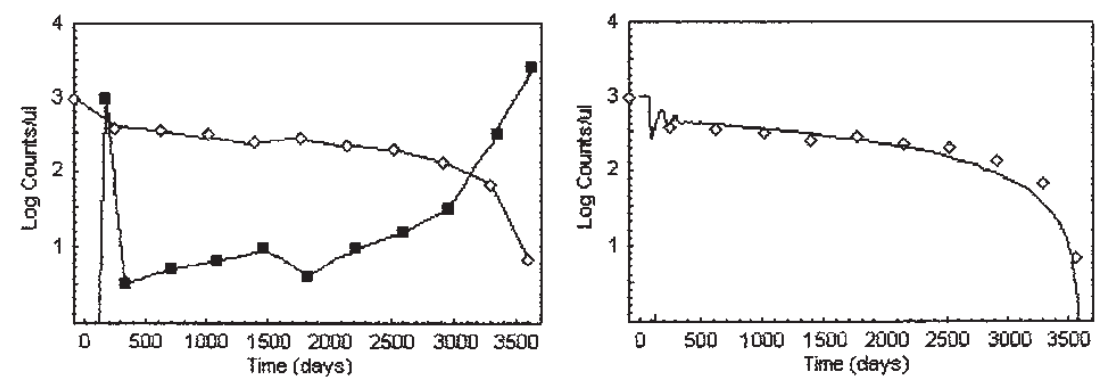

FIGURE 2 Patient data and predicted loss of CD4 + T cells. (left) Patient data for observed viral load $(\mathbf{\square})$ and loss of CD4 + T cells $(\diamond)$ taken from Fauci et al. (1996). In the first year approximately $40 \%$ of the T cells are lost. (right) Comparison of predicted (一) and observed $(\diamond)$ loss of CD4+ T cells in patients. Patient data follows a $10 \%$ a year decrease with $R^{2}=0.9099$ following the first year.

infections, which are strongly associated with AIDS, a sharp increase in viral production up to near 1000 fold has been reported (Moriuchi et al., 1998; Kalter et al., 1991). Orenstein et al. (1997) reported macrophage viral production that was too high to resolve by the techniques employed, indicating that increases in viral production may be higher still.

Using this information as a basis, equations that incorporate the concept of a macrophage second reservoir were derived and are presented below.

$$
\begin{aligned}
& \frac{\mathrm{d} T(t)}{\mathrm{d} t}=\lambda_{\mathrm{T}}-d_{\mathrm{T}} T-k_{\mathrm{T}} T V^{*}, \quad T(0)=T_{0} \\
& \frac{\mathrm{d} T \mathrm{i}(t)}{\mathrm{d} t}=k_{\mathrm{T}} T V^{*}-\delta_{\mathrm{T}} T, \quad T i(0)=\mathrm{Ti}_{0} \\
& \frac{\mathrm{d} M(t)}{\mathrm{d} t}=\lambda_{\mathrm{M}}-d_{\mathrm{M}} M-k_{\mathrm{M}} M V^{*}, \quad M(0)=M_{0} \\
& \frac{\mathrm{d} M \mathrm{i}(t)}{\mathrm{d} t}=k_{\mathrm{M}} M V^{*}-\delta_{\mathrm{M}} M, \quad \mathrm{Mi}(0)=\mathrm{Mi}_{0} \\
& \frac{\mathrm{d} V^{*}(t)}{\mathrm{d} t}=\pi_{\mathrm{T}} \mathrm{Ti}+\pi_{\mathrm{M}} \mathrm{Mi}-c V^{*}, \quad V^{*}(0)=V_{0}
\end{aligned}
$$

These expressions include activated CD4 $+\mathrm{T}$ cells $(T)$, infected CD4 $+\mathrm{T}$ cells $(T i)$, macrophage cells $(M)$, infected macrophage cells $(M i)$, and combined T cell and macrophage viral load $\left(V^{*}\right)$. In addition to coefficients

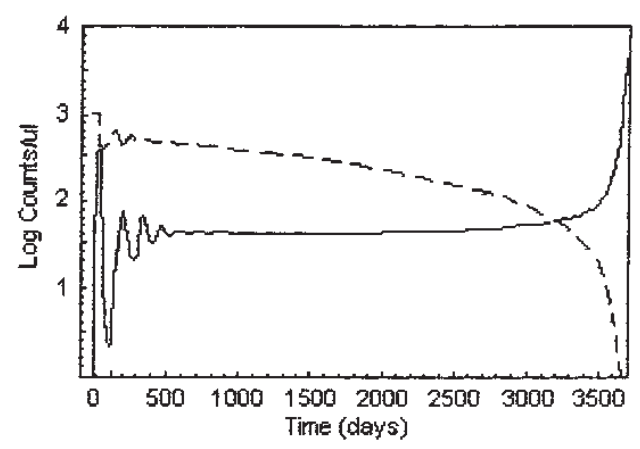

FIGURE 3 Clearance rate reduction model. Theoretical curves: viral load in copies/ul (-) and CD4 + T cell count in cells/ul, (- - -). defined previously, $\lambda_{\mathrm{M}}$ is the production rate of macrophages, $d_{\mathrm{M}}$ is the death rate of health macrophages, $\delta_{\mathrm{M}}$ the death rate of infected macrophages, $k_{\mathrm{M}}$ represents the infection rate of macrophages and $\pi_{\mathrm{M}}$ the production of virus by infected macrophages.

\section{Parameter Estimations}

Terms for the equations are also outlined in Table I above. For the purposes of calculation initial macrophage count, $M_{0}$, is taken as 200 macrophages ul ${ }^{-1}$ and all macrophage cells are assumed capable of being infected. The term for the death rate of healthy macrophages, $d_{\mathrm{M}}$, was derived from the assumption that the half-life of a tissue macrophage is 90 days. Although the exact half-life of a macrophage is not well defined, varying the half-life of macrophages from 45 days to 180 days did not have a significant effect on viral load and T cell counts (data not shown). Thus, the model is relatively insensitive to healthy macrophage lifetime.

Production of macrophages, $\lambda_{\mathrm{M}}=d_{\mathrm{M}} M_{0}$, is assumed to remain constant throughout infection. The half-life of infected macrophages, $\delta_{\mathrm{M}}$, has been estimated at 14.1 days (Perelson et al., 1996; Finzi et al., 1999; Zhang et al., 1999). The virus infectivity constant for macrophages $\left(k_{\mathrm{M}}\right)$ is assumed to be comparable to the virus infectivity constant for CD4 $+\mathrm{T}$ cells $\left(k_{\mathrm{T}}\right)$ based on early infection dynamics (Wodarz et al., 1999). Research has shown that $k_{\mathrm{M}}$ and $k_{\mathrm{T}}$ are widely variable depending on viral tropism as well as by the presence of cytokines and pathogenic infections (Kalter et al., 1991; Lederman et al., 1994; Verani et al., 1997; Moriuchi et al., 1998).

Production of virus by macrophages is low or undetectable in early infection and uses as T cell counts drop and opportunistic infections increase (Orenstein et al., 1997). This can be modeled by the expression:

$$
\pi_{\mathrm{M}}=0.1+1 \times 10^{(3 \mathrm{f})}
$$

In this formulation, macrophage viral production stimulated by opportunistic infections and other cellular components does not rise above 1000 times the original production in the time frame of the model, which 


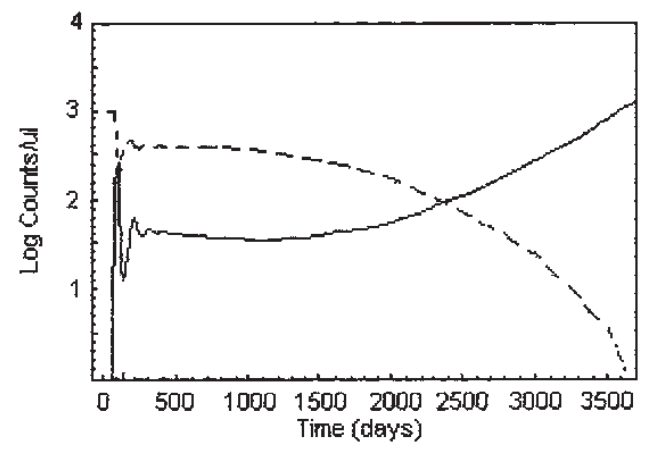

FIGURE 4 Macrophage reservoir model. Theoretical curves: Viral load in HIV copies/ul (-) and CD4 + T cell count in cells/ul, (- - -).

approaches the upper limit of macrophage virus production in the literature (Kalter et al., 1991). Figure 4 shows patient data (left) against the predicted dynamics of the infection with the added macrophage reservoir (right).

\section{Model Kinetics}

The shape of the theoretical curve follows the pattern seen in the patient data reasonably well. However, as noted earlier, the steady state value of the Fauci et al. (1996) patient data is about 10 times lower then that of the patient data from Stafford et al. (2000). As well, predicted viral load does not rise as steeply as it does in the patient data near the end of infection. This may reflect a variation in measurement techniques or possibly higher macrophage viral production than has been previously measured.

\section{DISCUSSION}

Although the dynamics of an HIV infection are complex, we have devised two models that follow the patterns of viral expression and $\mathrm{CD} 4+\mathrm{T}$ cell levels during the course of an entire infection. These models, as well as the model proposed by dos Santos and Coutinho (2001), rely on very different concepts. Aspects of all three models may be present in an actual infection.

In designing a model of AIDS, it is important to understand the dynamics of both host and viral systems. To be complete, a model of AIDS must include the hallmark decrease in CD4 $+\mathrm{T}$ cell counts and rise in viral load. Through the addition of a term derived from observed data (Fauci et al., 1996), the kinetics of CD4+ $\mathrm{T}$ cell production during infection were successfully modeled. The model corresponds to an annual decrease of $\mathrm{CD} 4+\mathrm{T}$ cells of $10 \%$ per year after an initial drop of about $40 \%$.

The paradox of high viral load in the absence of normal $\mathrm{CD} 4+\mathrm{T}$ cell values is central to the theories that purport to explain the onset of AIDS. In additional to the explanation proposed by dos Santos and Coutinho (2001), essentially two hypotheses remain. First, if it is assumed that $\mathrm{CD} 4+\mathrm{T}$ cells remain the primary source of virus throughout infection, then the kinetics of the $\mathrm{T}$ cell/virus relationship must change. A reasonable theory is that the virus is not cleared as efficiently as disease progresses. This was modeled by the addition of a term that decreases clearance rate, $c$, by the same rate as the decrease in $\mathrm{CD} 4+\mathrm{T}$ cell production.

The effect of this term on the model shows marked sensitivity to changes in clearance rate. For example, doubling the viral clearance rate from $c=3$ to $c=6$ decreases steady state viral load approximately 3 fold and halving the clearance rate from $c=3$ to $c=1.5$ more than doubles it. Ho et al. (1995) suggest that clearance rate remains constant over the course of infection based on individual measurements that vary as much as 2.5 fold.

We have shown here that a 2 fold change in the viral clearance rate has a large effect on viral load. In addition, recent studies report clearance rate measurements as much as 10 times faster than those measured by Ho et al. (1995) (Ramratnam et al., 1999). Thus, there is greater than 10 fold variation in measured clearance rates, adequate to account for the dramatic changes in viral load seen over the course of AIDS within the error of current measurements. Despite this, little attention is given in the literature to the effects of reduction in viral clearance rate.

The second hypothesis is that viral production must increase as $\mathrm{T}$ cell counts decrease. This requires the presence of a second viral reservoir capable of essentially replacing the waning $\mathrm{CD} 4+\mathrm{T}$ cell reservoir. Many other types of cells are capable of becoming productively infected, but macrophages appear particularly important (Ho et al., 1986; Nicholson et al., 1986). Throughout the early phases of infection, macrophage viral production is low and $\mathrm{CD} 4+\mathrm{T}$ cells are clearly the primary source of virus. However, studies have shown that in the presence of opportunistic infections, macrophage virus production increases greatly (Orenstein et al., 1997). In the current model, macrophage viral production increases as a function of time paralleling the decrease in CD4 $+\mathrm{T}$ cell counts and the observed rise in the occurrence of opportunistic infections leading up to AIDS. The predicted rise in virus is not as sharp in the model as it is in the observed data, which may be due either to other important virus producing cell types or to greater macrophage viral production than has previously been reported.

Simple models that focus on the most important aspects of the HIV/host relationship are essential to the study of AIDS. Much research must be done to assess the quantitative importance of each of these models on the dynamics on HIV infection. However, the macrophage reservoir is well supported in the literature. These studies strongly suggest that infected macrophages are capable of producing the large amount of virus seen late in infection. This information may prove valuable in the treatment of HIV infected patients. For instance, it has been observed that reverse transcriptase inhibitors, such as PMBA, used in rhesus macaque SHIV research are not effective on 
virally infected macrophages (Igarashi et al., 2001). If it is found that macrophages account for much of the viral load in humans late in infection, this could have an effect on chosen methods of treatment depending on the stage of disease.

Similarly, although a definitive study on changes in viral clearance rate has not yet been performed, changes in the clearance rate can clearly account for the dynamics seen in AIDS. If it is discovered that decreasing viral clearance rates are common to HIV infection, then alternate methods of treatment may be sought, especially treatments that enhance the immune system or affect clearance rate.

\section{SUMMARY}

We have shown that a simple target-cell-limited model can be modified to include dynamics of the entire course of HIV infection and AIDS. Two models have been proposed here, and results concur with observed data and evidence in the literature. Though much research must be done to determine the complete dynamics of AIDS, simple models such as these may help to further the understanding of the pathogenesis of HIV.

\section{References}

Barr, C.E. (1992) "Oral diseases in HIV-1 infection”, Dysphagia 7(3), $126-137$.

Bonhoeffer, S., May, R.M., Shaw, G.M. and Nowak, M.A. (1997) "Virus dynamics and drug therapy", Proceedings of the National Academy of Sciences of the United States of America 94(13), 6971-6976.

Bouhdoud, L., Villain, P., Merzouki, A., Arella, M. and Couture, C. (2000) "T-cell receptor-mediated anergy of a human immunodeficiency virus (HIV) gp120-specific CD4(+) cytotoxic T-cell clone, induced by a natural HIV type 1 variant peptide", Journal of Virology 74(5), 2121-2130.

Douek, D.C., McFarland, R.D., Keiser, P.H., Gage, E.A., Massey, J.M., Haynes, B.F., Polis, M.A., Haase, A.T., Feinberg, M.B., Sullivan, J.L., Jamieson, B.D., Zack, J.A., Picker, L.J. and Koup, R.A. (1998) "Changes in thymic function with age and during the treatment of HIV infection", Nature 396(6712), 690-695.

Douek, D.C., Betts, M.R., Hill, B.J., Little, S.J., Lempicki, R., Metcalf, J.A., Casazza, J., Yoder, C., Adelsberger, J.W., Stevens, R.A., Baseler, M.W., Keiser, P., Richman, D.D., Davey, R.T. and Koup, R.A. (2001) "Evidence for increased T cell turnover and decreased thymic output in HIV infection", Journal of Immunology 167(11), 6663-6668.

Fauci, A.S., Pantaleo, G., Stanley, S. and Weissman, D. (1996) "Immunopathogenic mechanisms of HIV infection", Annals of Internal Medicine 124, 654-663.

Finzi, D., Blankson, J., Siliciano, J.D., Margolick, J.B., Chadwick, K., Pierson, T., Smith, K., Lisziewicz, J., Lori, F., Flexner, C., Quinn, T.C., Chaisson, R.E., Rosenberg, E., Walker, B., Gange, S., Gallant, J. and Siliciano, R.F. (1999) "Latent infection of CD4+ T cells provides a mechanism for lifelong persistence of HIV-1, even in patients on effective combination therapy", Nature Medicine 5(5), $512-517$.

Gumel, A.B., Loewen, T.D., Shivakumar, P.N., Sahai, B.M., Yu, P. and Garba, M.L. (2001) "Numerical modelling of the perturbation of HIV-1 during combination antiretroviral therapy", Computers in Biology and Medicine 31(5), 287-301.

Haase, A.T. (1999) "Population biology of HIV-1 infection: viral and CD4+ T cell demographics and dynamics in lymphatic tissues", Annual Review of Immunology 17, 625-656.

Hansen, R.S., AhLoy, R.D. and Meyer, R.D. (1985) "The acquired immunodeficiency syndrome", Emergency Medicine Clinics of North America 3(1), 3-23.
Ho, D.D., Rota, T.R. and Hirsch, M.S. (1986) "Infection of monocyte/macrophages by human T lymphotropic virus type III", Journal of Clinical Investigation 77(5), 1712-1715.

Ho, D.D., Neumann, A.U., Perelson, A.S., Chen, W., Leonard, J.M. and Markowitz, M. (1995) "Rapid turnover of plasma virions and CD4 lymphocytes in HIV-1 infection", Nature 373(6510), $123-126$.

Igarashi, T., Brown, C.R., Endo, Y., Buckler-White, A., Plishka, R., Bischofberger, N., Hirsch, V. and Martin, M.A. (2001) "Macrophage are the principal reservoir and sustain high virus loads in rhesus macaques after the depletion of $\mathrm{CD} 4+\mathrm{T}$ cells by a highly pathogenic simian immunodeficiency virus/HIV type 1 chimera (SHIV): implications for HIV-1 infections of humans", Proceedings of the National Academy of Sciences of the United States of America 98(2), 658-663.

Kalter, D.C., Nakamura, M., Turpin, J.A., Baca, L.M., Hoover, D.L., Dieffenbach, C., Ralph, P., Gendelman, H.E. and Meltzer, M.S. (1991) "Enhanced HIV replication in macrophage colony-stimulating factor-treated monocytes", Journal of immunology (Baltimore, Md.: 1950) 146(1), 298-306.

Kapadvanjwala, M. and Sofer, S.S. (1989) "A mathematical simulation of the AIDS patient and extracorporeal detoxification", Computers in Biology and Medicine 19(6), 461-470.

Lederman, M.M., Georges, D.L., Kusner, D.J., Mudido, P., Giam, C.Z. and Toossi, Z. (1994) "Mycobacterium tuberculosis and its purified protein derivative activate expression of the human immunodeficiency virus", Journal of Acquired Immune Deficiency Syndromes 7(7), 727-733.

Maas, J.J., Roos, M.T., Keet, I.P., Mensen, E.A., Krol, A., Veenstra, J., Schellekens, P.T., Jurriaans, S., Coutinho, R.A. and Miedema, F. (1998) "In vivo delayed-type hypersensitivity skin test anergy in human immunodeficiency virus type 1 infection is associated with T cell nonresponsiveness in vitro", Journal of Infectious Diseases 178(4), 1024-1029.

Matsuo, K., Honda, M., Shiraki, K. and Niimura, M. (2001) "Prolonged herpes zoster in a patient infected with the human immunodeficiency virus", Journal of Dermatology 28(12), 728-733.

Mittler, J.E., Markowitz, M., Ho, D.D. and Perelson, A.S. (1999) "Improved estimates for HIV-1 clearance rate and intracellular delay", Aids 13(11), 1415-1417.

Moriuchi, M., Moriuchi, H., Turner, W. and Fauci, A.S. (1998) "Exposure to bacterial products renders macrophages highly susceptible to Ttropic HIV-1", The Journal of Clinical Investigation 102(8), $1540-1550$

Nicholson, J.K., Cross, G.D., Callaway, C.S. and McDougal, J.S. (1986) "In vitro infection of human monocytes with human T lymphotropic virus type III/lymphadenopathy-associated virus (HTLV-III/LAV)", Journal of Immunology 137(1), 323-329.

Nowak, M.A. and Bangham, C.R. (1996) "Population dynamics of immune responses to persistent viruses", Science 272(5258), 74-79.

Orenstein, J.M., Fox, C. and Wahl, S.M. (1997) "Macrophages as a source of HIV during opportunistic infections", Science 276(5320), $1857-1861$

Pantaleo, G., Graziosi, C. and Fauci, A.S. (1993) "New concepts in the immunopathogenesis of human immunodeficiency virus infection", The New England Journal of Medicine 328(5), 327-335.

Perelson, A.S. and Nelson, P.W. (1999) "Mathematical analysis of HIV-1 dynamics in vivo", Society for Industrial and Applied Mathematics Review 41, 3-44.

Perelson, A.S., Neumann, A.U., Markowitz, M., Leonard, J.M. and Ho, D.D. (1996) "HIV-1 dynamics in vivo: virion clearance rate, infected cell life-span, and viral generation time", Science 271(5255), $1582-1586$.

Ramratnam, B., Bonhoeffer, S., Binley, J., Hurley, A., Zhang, L., Mittler, J.E., Markowitz, M., Moore, J.P., Perelson, A.S. and Ho, D.D. (1999) "Rapid production and clearance of HIV-1 and hepatitis $\mathrm{C}$ virus assessed by large volume plasma apheresis", Lancet 354(9192), $1782-1785$

Rosenberg, Y.J., Zack, P.M., Leon, E.C., White, B.D., Papermaster, S.F., Hall, E., Greenhouse, J.J., Eddy, G.A. and Lewis, M.G. (1994) "Immunological and virological changes associated with decline in CD4/CD8 ratios in lymphoid organs of SIV-infected macaques", AIDS Research and Human Retroviruses 10(7), 863-872.

Sachsenberg, N., Perelson, A.S., Yerly, S., Schockmel, G.A., Leduc, D., Hirschel, B. and Perrin, L. (1998) "Turnover of CD4+ and CD8+ T lymphocytes in HIV-1 infection as measured by Ki-67 antigen", The Journal of Experimental Medicine 187(8), 1295-1303. 
dos Santos, R.M.Z. and Coutinho, S. (2001) "Dynamics of HIV infection: a cellular automata approach", Physical Review Letters 87(16), 168102-1-168102-4.

Schacker, T., Collier, A.C., Hughes, J., Shea, T. and Corey, L. (1996) "Clinical and epidemiologic features of primary HIV infection", Annals of Internal Medicine 125(4), 257-264.

Schnittman, S.M., Lane, H.C., Greenhouse, J., Justement, J.S., Baseler, M. and Fauci, A.S. (1990) "Preferential infection of CD4+ memory $\mathrm{T}$ cells by human immunodeficiency virus type 1 : evidence for a role in the selective T-cell functional defects observed in infected individuals", Proceedings of the National Academy of Sciences of the United States of America 87(16), 6058-6062.

Stafford, M.A., Corey, L., Cao, Y., Daar, E.S., Ho, D.D. and Perelson, A.S. (2000) "Modeling plasma virus concentration during primary HIV infection", Journal of Theoretical Biology 203(3), 285-301.
Verani, A., Scarlatti, G., Comar, M., Tresoldi, E., Polo, S., Giacca, M., Lusso, P., Siccardi, A.G. and Vercelli, D. (1997) "C-C chemokines released by lipopolysaccharide (LPS)-stimulated human macrophages suppress HIV-1 infection in both macrophages and T cells", The Journal of Experimental Medicine 185(5), $805-816$

Wodarz, D., Lloyd, A.L., Jansen, V.A. and Nowak, M.A. (1999) "Dynamics of macrophage and T cell infection by HIV", Journal of Theoretical Biology 196(1), 101-113.

Zhang, L., Ramratnam, B., Tenner-Racz, K., He, Y., Vesanen, M., Lewin, S., Talal, A., Racz, P., Perelson, A.S., Korber, B.T., Markowitz, M. and Ho, D.D. (1999) "Quantifying residual HIV-1 replication in patients receiving combination antiretroviral therapy", The New England Journal of Medicine 340(21), $1605-1613$. 


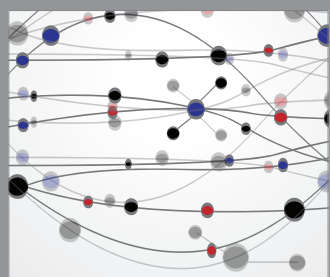

The Scientific World Journal
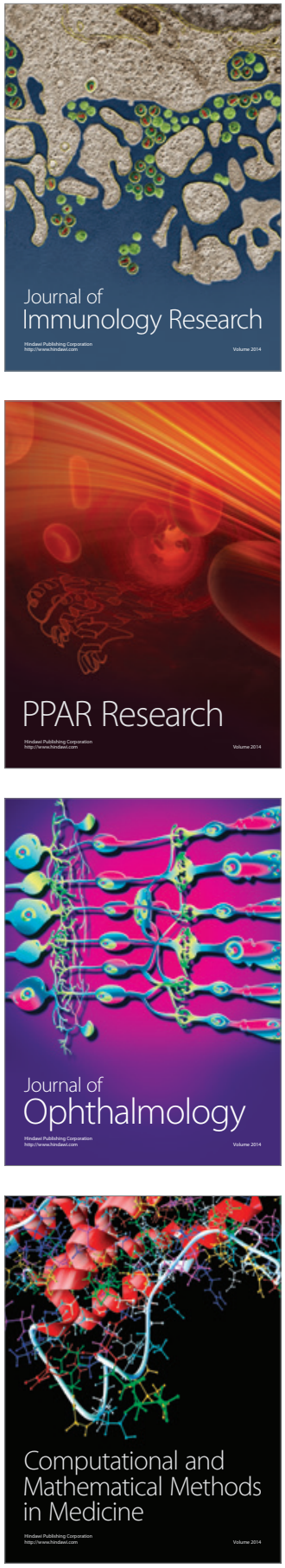

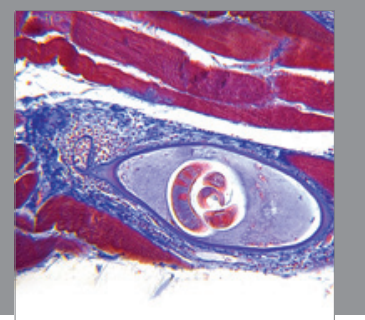

Gastroenterology

Research and Practice
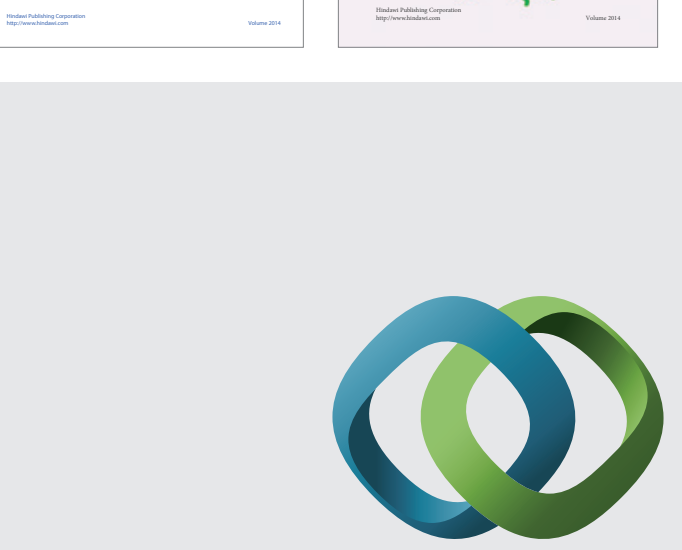

\section{Hindawi}

Submit your manuscripts at

http://www.hindawi.com
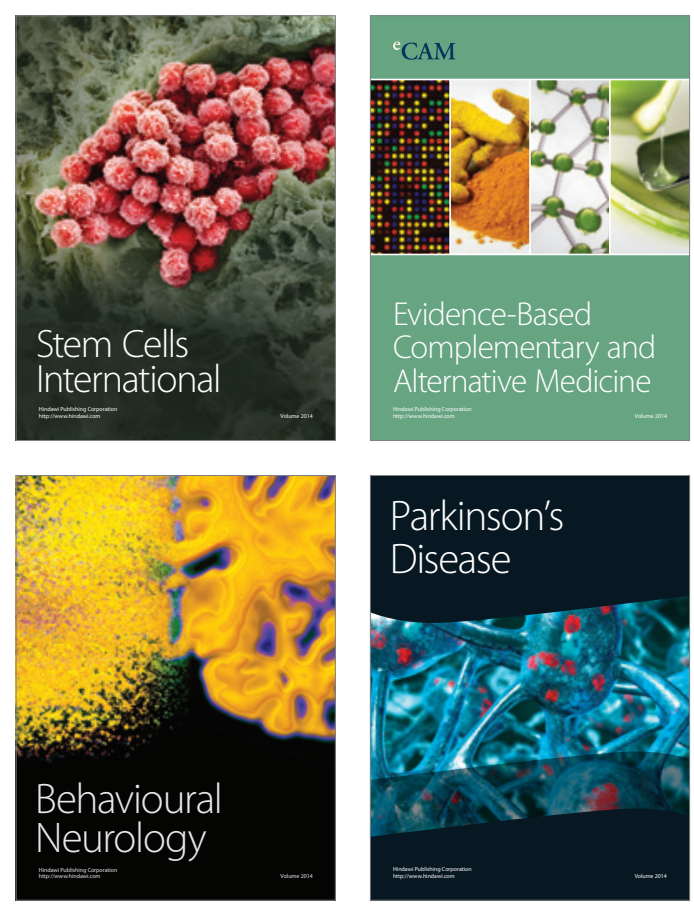

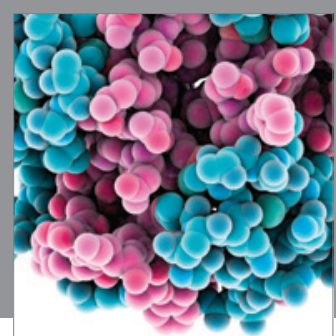

Journal of
Diabetes Research

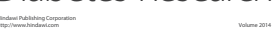

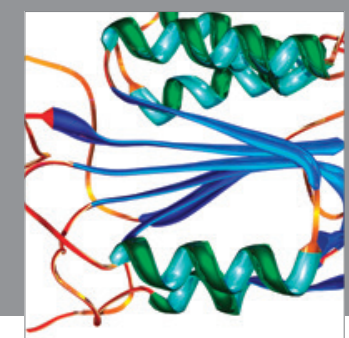

Disease Markers
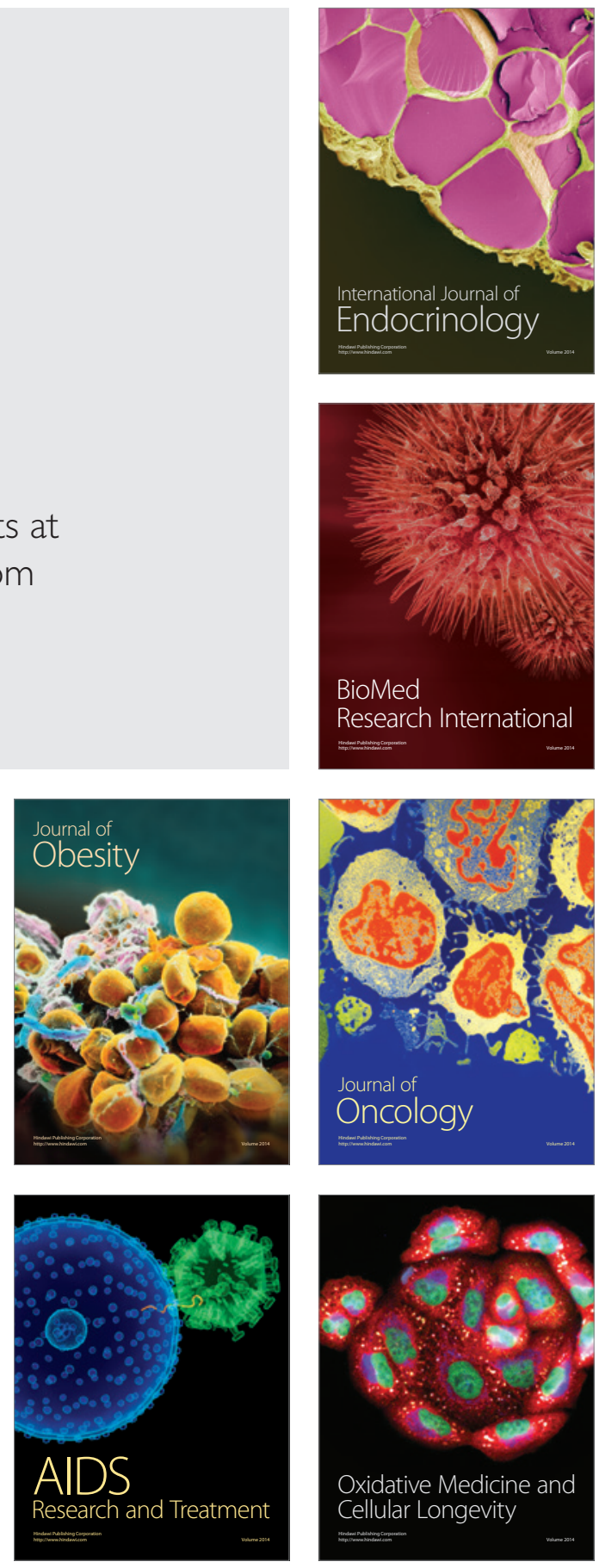